\title{
Regulation of financial services in the UK and Japan - comparing the conduct of business rules
}

\author{
by Mitsue Miyajima
}

W hile the UK's Financial Services and Markets Bill (FSMB) is undergoing parliamentary scrutiny, and is now expected to be enacted sometime towards the end of this year, the Japanese Financial Services Bill, Kinyuu Saabisu Hoan, will not be presented to the Diet in the year 2000 as previously hoped and will have to wait until January 2001.

The Financial System Council (FSC) formed under the Financial System Planning Bureau (FSPB) within the Ministry of Finance $(\mathrm{MoF})$ came to the conclusion at the end of October 1999 that they simply would not have enough time to complete all the discussions, consultations and other necessary preparations prior to its presentation to the Diet. Instead, it was decided to present the Bill for the Law concerning Rules of Sales and Promotion of Financial Products (LRSPFP) as the first step towards the enactment of a Japanese version of the Financial Services Act (JFSA).

\section{BACKGROUND}

On 30 November 1999 the Consumer Policy Committee of the Social Policy Council in the Economic Planning Agency (EPA) published its final report for legislation of the Consumer Contract Act. The path leading to the final report had been rocky from the point where the serious discussions on it first started in the spring of 1998. The committee had the unenviable task of trying to please both consumers and business groups. The Bill, originally planned for a year earlier, was presented to the new ordinary Diet session which started in January 2000.

The right to cancel contracts resulting from non-disclosure of material information, misrepresentation, etc., and to make contracts with unfair terms void, are included in the Bill, but the duty of goods/service providers to provide consumers with relevant information is not stipulated; they only have to do their best. This attracted much criticism from consumer groups, as it appears that business groups had succeeded in persuading government officials to make such a compromise. Some say that the EPA, fated to lose existence in the reorganisation of the central government in January next year, is desperate to leave some notable achievements in its history. The FSPB, which is also to be merged into the new Financial Services Agency (an expanded version of the current Financial Supervisory Agency) to be established in July this year, converting the MoF into a new Treasury Ministry at the same time, felt it necessary to produce corresponding legislation specifically covering financial services.

\section{THE PROCESS TOWARDS THE LRSPFP BILL}

The Financial System Council (FSC) was formed in August 1998 by the then Finance Minister to study measures for improving the financial regulatory and securities transaction system for the purpose of 'creating a safe and vigorous financial system fit for the 21 st century'. The FSC comprises two committees - the First Committee and the Second Committee, the latter's tasks being mainly to deal with bad loan problems and the revitalisation and stabilisation of the financial system.

The First Committee has been working on a desirable financial system for the 21 st century and the framework of rules to underpin it, the ultimate goal being enactment of the JFSA, which is regarded as the essential regulatory infrastructure. In order to legislate UK-style financial services law, Japan has to adopt a different concept: a regulatory system catering for financial products rather than institutions or business entities, which in turn requires the restructuring of civil law rules. Since such radical changes of the system cannot be achieved on a purely theoretical basis, the FSC decided to focus first on the concrete measures for particularly urgent issues arising under the reform programme for the entire financial system - christened the Japanese version of the 'Big Bang'. (By the end of 1998, 26 revised statutes had been passed in the Diet, including the Foreign Exchange and Securities Law and Banking Law, and 38 related statutes were amended.)

Two areas have been identified:

(1) rules for conduct of sales and promotion of financial products that are expected to become increasingly complex and cross-sectoral; and

(2) collective investment schemes.

A working group comprised mainly of academics, lawyers and financiers has tackled each area. The FSC published its first interim report, based on the reports from these working groups, on 6 July 1999 and, after a public consultation exercise and further reports from the working groups, the second on 21 December 1999. The FSC set 14 January 2000 as the deadline for accepting opinions from the public on its second report - a little over three weeks, if one does not count holidays in the festive season.

\section{LRSPFP BILL AND UK FSA'S HANDBOOK OF RULES \& GUIDANCE}

The framework of the 'rules' (i.e. the draft LRSPFP Bill) was set out in detail in the working group report of 7 December 1999, on which the FSC based its second interim report. The LRSPFP Bill was to be prepared and introduced in the ordinary Diet session by mid-March 2000, with the aim of enactment before the end of the session in mid-June.

The rules have two main pillars:

- the obligation on financial service providers to give customers information necessary for proper decision-making; and

- liability to compensate for the loss resulting from their failure to comply with the rules.

Under the proposals lenders will incur civil liability in certain circumstances, reflecting concerns over the much-publicised issue of lending combined with high-risk products. However, 
due to time constraints, they do not include new measures for dispute resolution or compensation schemes; nor are other important issues, such as investor suitability tests or unsolicited calls, properly addressed. They will be dealt with this year, and concrete ideas are to be proposed in the FSC's final report expected in June 2000. For the moment, the following five issues are covered by the rules:

(1) financial products to be covered by the law;

(2) financial service providers in the context of the law;

(3) duty to explain;

(4) liability to compensate for loss due to non-compliance with the rules; and

(5) improper solicitation for transactions.

It is not intended to examine these in detail here, but rather to consider the rules as a whole in comparison with the UK Financial Services Authority's Handbook of Rules and Guidance ('the FSA Handbook') which is currently being worked on by the FSA's Policy Co-ordination Department.

While the Japanese authority is struggling with just one aspect of the conduct of business rules, which are to be created virtually from scratch, their counterpart in the UK seems to have a task of completely opposite nature. The latter has to bring together a diverse set of existing measures such as the conduct of business requirements of the three SROs (SFA, IMRO, PIA), various old SIB rules and other regulations applicable across the board (e.g. unsolicited calls, cancellation, promotion of unregulated schemes), as well as a small amount of relevant material in statutory instruments (e.g. on advertising by overseas banks and insurance companies). In addition, on the 'wholesale' side, there are the 'Section 43' regime (with the London Code of Conduct) operated by the Bank of England until May 1998 and the professional dealings regime operated by the SFA. The issue of whether to retain an intermediate regime for the protection of 'non-private' customers also has to be considered. The FSA's stance in the face of this enormous task is to build on current approaches and also to differentiate appropriately within them between the different types of firm and lines of business. Its aim is to combine the best features of each existing regime in accordance with its overall objectives and approach.

The Conduct of Business Sourcebook is contained in the handbook referred to above. This sourcebook is only one part of the handbook, which is comprised of four main blocks:

(1) high-level principles;

(2) business standards;

(3) regulatory processes; and

(4) redress.

The business standards block contains all the major sourcebooks, including the Conduct of Business Sourcebook as well as the Prudential and Market Conduct Sourcebooks. Each provides rules and guidance deriving from the legislative powers conferred on the FSA by the FSMB (Chapter I: Rule-making powers in Part IX: Rules and Guidance) - a rule-making instrument (s. 123).

The Financial Services Act 1986 contains a chapter called 'Conduct of Business' (Part I, Chapter V). Among its 17 sections are rules for conduct of business, including misleading statements and practices, cancellation rules, clients' money, unsolicited calls and restrictions on advertising. In addition, s. 48 specifies provisions that may be made in the conduct of business rules, such as the manner of market-making, disclosure of commission to be charged/earned and Chinese walls. The FSMB, on the other hand, does not have a corresponding chapter, merely a reference to misleading statements and practices (in Part XXV: Offences, s. 341). Instead, it leaves all those details to secondary legislation by conferring powers on the Treasury (by statutory instruments) or the FSA (by rule-making instruments), keeping the scope of the primary legislation to the basics with a narrower focus - i.e. a high-level framework. This is intended to 'future proof' the legislation and allow the UK system to be best placed to reflect the opportunities of new and rapidly evolving communications technology. Exercising the power thus conferred, the Treasury is preparing draft orders covering financial promotion (cl. 19) and regulated activities (cl. 20), etc. Likewise, the FSA, as mentioned above, is compiling the Business Standards Sourcebooks (cl. 110).

The Japanese LRSPFP will be a piece of primary legislation, but it seems to cover quite detailed points, judging from the contents of the rules mentioned above. Although it will be left for secondary legislation to specify in detail the financial products to be covered by the law, it seems that the very basic and important matter of comprehensive categorisation of financial products is missing. Some have expressed concern over the proposed method of individually listing products to be brought under the scope of the law. They think the method will not be capable of catching up with the speed of new product development and is thus not sufficiently 'future proofed'.

When one compares the draft LRSPFP Bill with the UK's FSMB, it is obvious that the former corresponds with only a tiny piece of the latter. Nevertheless, the proposed rules have met with severe criticism, especially from the Japan Federation of Bar Associations.

\section{OMISSIONS AND SHORTCOMINGS}

The Japan Federation of Bar Associations (JFBA) submitted its opinion on the report on 7 January 2000. As an advocate of greater consumer protection, it acknowledged that the second report was an improvement on the first, in which efficiency of the financial system had been placed above fairness to consumers on its list of targets. However, it highlighted a number of points that require further consideration or a complete change of views. Each of those points will be considered below.

\section{Financial products to be covered}

While acknowledging the importance of comprehensive coverage of financial products in order to cope with the rapidly changing financial/technological environment, the FSC concluded that it was difficult to achieve at this stage and left it to future discussions. Instead, the law is to list as many categories of products as possible, allowing it to include similar products, and the secondary legislation is to specify each individual product. Basically, those specified in existing laws such as the Securities and Exchange Law and the Banking Law are to be listed - such as securities, deposits, insurance, investment trusts, futures and options. 
The JFBA thinks this approach would allow the creation of financial products unregulated by the law and unscrupulous financial service providers would find loopholes in the law enabling them to prey on unsophisticated consumers. In the past, it says, the Japanese legislature tended to react to unfortunate incidents where consumers suffered loss instead of making pre-emptive laws. The legislators are recommended not to make the same mistake in future.

In the UK's FSMB, certain investment activities are specified as 'regulated activities' for the purpose of general supervision by FSA. Section 20 and Sch. 2 of the Bill provide the framework, and the Treasury is to extend its scope by an order specifying those to be included ('broadly similar' activities are specified as 'controlled activities' for the purpose of the financial promotion exemptions rule under s. 19). Regulated activities included in Part I of Sch. 2 are: dealing in/arranging deals in/managing investments, investment advice, deposit taking, safekeeping and administration of assets, establishing collective investment schemes and using computer-based systems for giving investment instructions. The Draft Order issued in February 1999 specifies 19 activities with more concrete decriptions. Part II of Schedule 2 provides a list of investments in the context of Part I activities - 14 categories, including securities, deposits, options, futures, contracts of insurance and others. The same Draft Order names 14 types of investment but excludes 'loans secured on land' (thus mortgages are not currently within the jurisdiction of FSA); instead insurance contracts are divided into two - general insurance and long term insurance.

It would be interesting to find out whether the UK's approach would satisfy the JFBA.

\section{JIGSAW PUZZLE}

Someone has described the Japanese legislators' approach to the JFSA as 'struggling to complete a jigsaw puzzle while knowing from the start that many pieces are missing'. The biggest and most important of these pieces is that which covers the whole financial services industry, where products or institutions are merging across sectoral boundaries.

\section{Financial service providers and their practice}

The JFBA is pleased that the law is to cover widely those who are involved in sales and/or promotion of financial products, including agents or intermediaries. However it advises the legislator to amend the wording so as to cover a wider range of people engaging in the sales and/or promotion of complex financial products. It is important, the JFBA stresses, to prevent the kinds of tragedies brought about by lending combined with high-risk financial products (where banks sold insurance products without a licence to do so, which, rightly or wrongly, allowed them to argue that they were outside the ambit of legal liability).

In the UK, only authorised persons (and exempt persons in certain respects) will be allowed to engage in regulated investment activities. An unauthorised person who engages in a regulated activity in the UK will be guilty of an offence and liable to a maximum of two-years in prison. In addition, the conduct of business rules adopted by SROs such as the SFA provide clear guidance for dealing with packaged products. Polarisation was once a hot topic among providers of such products.

The starting point for regulating those engaged in investment activities differs very much between the two countries.

\section{Duty to explain}

The focus of discussions here is what to explain and how. It is proposed that the material points necessary for consumers to assess potential risks should be explained. The features and structure of the product, with inherent risks, are to be explained together with the risk element itself. However, secondary legislation can limit those requirements for well-known products involving well-acknowledged risks. It is added that the duty should be waived if the counterparts are professionals or if consumers themselves agree not to have any explanation. It is also proposed that the details should be set out and published in the industry's guidelines and companies' internal manuals.

The JFBA points out first of all that it is unreasonable to discuss the duty to explain in isolation. Other important rules relating to unsolicited calls or customer suitability tests are left to future discussions or to be dealt with in companies' internal manuals only. Consumer ability to understand a product and to assess its inherent risks varies widely, and consumers still tend to rely on, rather too gullibly, the advice given by financial service providers. It is emphasised that the duty to assess the suitability of a product for a customer should be stipulated in the law. It is also pointed out that unscrupulous persons might persuade customers to agree to have the explanation waived and to sign a form to that effect.

The voluntary Banking Code subscribed to by the UK banks and building societies clearly sets out, as a matter of course and without argument as to whether or not it is necessary, that information on services and products is to be given and help will be offered if customers do not understand it. Help for customers to choose a service or product to fit their needs and to understand the financial implications of choosing products such as mortgages is also to be given. The SFA Rulebook, for example, also has many pages of 'conduct of business' rules covering customer relations (including customer understanding, suitability of product), advertising and marketing, unsolicited calls, packaged products and so on.

It is a little puzzling why in Japan so much detail on a subject needs to be stipulated in primary legislation. Perhaps it is due to the difference in the legal system and culture of the two countries - i.e. common law versus civil law.

\section{Legal liability to compensate}

It is proposed that the liability to compensate for loss resulting from non-compliance with the rules should be accepted, taking into account precedents established by the courts and liability in tort set out in the Civil Code. The mechanism for deciding exactly who should pay, especially in cases where more than one service provider is involved in a transaction, is to be discussed in the future. It is suggested that the enforceability of agreements will not be affected, since the loss suffered from financial transactions can be compensated financially. 
The JFBA's view on this is that the principle should be applied to most other rules, in addition to that of the duty to explain, instead of leaving the matter to industries' or companies' voluntary compliance practice.

The UK's FSMB stipulates civil or criminal liabilities for various situations. With respect to contravention of rules, however, cl. 120 only provides that it is actionable at the suit of a private person who suffers loss as a result of the contravention.

In its latest Opinion, the JFBA did not specifically argue about the enforceability of agreements entered into by consumers persuaded by service providers who fail to comply with the rules. However, in the past it has always recommended the legal effect of making agreements void or unenforceable and giving consumers the right to cancellation, repudiation, etc. This time it is arguing generally for clear legal consequences to be stipulated for cases of non-compliance. The working group finds it difficult to stipulate legal effects to make agreements void or to give consumers the right to cancel or repudiate in view of the strict Civil Code principles in the matter.

The enforceability of agreements in the case of contravention of rules is touched upon in cl. 121 of the FSMB, which provides that no contravention makes a transaction void or unenforceable.

\section{Other improper sales practice, etc.}

The FSC believe that fraudulent practices should be dealt with under the proposed Consumer Contracts Act mentioned at the beginning of this article - thus no separate provisions for financial services are required in the LRSPFP.

The JFBA argues that the special features of financial services demand further rules that can cover all the financial institutions. The UK's FSMB, in cl. 341, stipulates that 'a person' who, by fraudulent practices described in subs. (1), makes another person enter into a relevant agreement in any relevant investments is guilty of an offence and liable to imprisonment (a maximum of seven years) or fine, or both. The matter is not left to other relevant statutes, such as the Misrepresentation Act 1967.

As mentioned earlier, the rules for unsolicited calls, advertisements, and sale of unsuitable products, etc, will not be stipulated in the law but left to the industry's own compliance practice. It is proposed that publication of internal manuals, and compliance with them, should be made a legal requirement. Not surprisingly, the JFBA demands the authority's determined approach to it.

The regime specified in cl. 19 of the FSMB moves away from the existing classifications of advertisement and unsolicited calls, introducing instead the more media-neutral concept (in order to cover e-commerce, for example) of an 'invitation or inducement' to engage in investment activity. In addition, solicited calls, as well as unsolicited calls, are subject to the basic prohibition on unapproved financial promotions - thus bringing them potentially within the ambit of criminal offence.

It is sad to have to admit how far behind Japanese legislation remains.

\section{CONCLUSION}

Someone has described the Japanese legislators' approach to the JFSA as 'struggling to complete a jigsaw puzzle while knowing from the start that many pieces are missing'. The biggest and most important of these pieces is that which covers the whole financial services industry, where products or institutions are merging across sectoral boundaries.

The common purpose for legislating both the FSMB and the JFSA must be to update the law so that it will be capable of coping with globalisation, the ever changing nature of the financial services industry and rapidly advancing information and communication technology. The Japanese legislators are studying very closely the UK's progress in its financial regulatory reforms and the FSMB in particular, but they have not yet managed to mirror the three principal pillars of the FSMB: i.e. a system to embrace the whole financial industry and its products, a dispute-resolution mechanism and compensation schemes.

Japan has her own particular needs. For example, she must create a system capable of preventing the recurrence of social problems such as the personnal tragedies caused by lending combined with high-risk products, and to find a more efficient way of investing private assets of 1,200 trillion yen to provide for the rapidly-ageing population. It is a huge task to satisfy all the demands coming from both the financial and economic fronts, but it may be more effectively tackled if the stage for it is built on the well-principled JFSA as the essential regulatory infrastructure for the financial system in the 21 st century.

The chairman of the FSC has admitted that the rules have shortcomings. It is difficult and time consuming to adjust and co-ordinate between several government offices, each of which is responsible for a particular industry. The Ministry of Posts and Telecommunications in particular represents a piece that is difficult to fit into the jigsaw puzzle - as a provider of financial services such as savings and insurance and a keen candidate for dealing with investment trusts.

The FSC has not enjoyed much plain sailing so far and it seems unlikely that the and going will get any easier. They have expended so much time and effort to complete what corresponds with only a very small piece of the UK Handbook jigsaw. It is hard to estimate how long it will take for Japan to have a proper financial services law authority, especially when each piece needed to complete the whole picture lacks a clear shape - not to mention those that are missing altogether.

\section{Mitsue Miyajima}

Rearch officer, IALS

Since this article was written some of the clauses in the Financial Services and Markets Bill have been subjected to changes of numbering. 